\title{
Evaluation of the combustion noise of passenger car diesel engines
}

\author{
Johannes Seifriedsberger $^{1} \cdot$ Peter Rumplmayr $^{1}$ (I)
}

Received: 6 November 2015/Accepted: 29 February 2016/Published online: 29 March 2016

(c) The Author(s) 2016. This article is published with open access at Springerlink.com

\begin{abstract}
The present article is concerned with the investigation of the combustion noise of passenger car diesel engines, which, especially in part load conditions, is clearly perceptible for passengers and passers-by. On the one hand, the state-of-the-art is shown by comparing three actual passenger cars on an acoustic roller test bench. On the other hand, a profound analysis of the combustion process is performed on an engine test bed, with the main focus on the illustration of dependencies between several operation parameters and the combustion noise as well as the transmission from the combustion chamber to the environment. Beside steady-state operating points the transient behavior is also investigated.
\end{abstract}

\section{Introduction}

Driven by the increasing demand of customers for comfort, the subject of automotive and engine acoustics is rising in its importance in the process of vehicle development. Higher expectations regarding vehicle interior noise are accompanied by the requirement of a lowered exterior noise, which can be considered as a pollutive factor. More often, a well-targeted improvement of the sound characteristics has replaced a simple reduction of the noise level.

Peter Rumplmayr

rumplmayr@ivt.tugraz.at

Johannes Seifriedsberger

seifriedsberger@ivt.tugraz.at

1 Institute of Internal Combustion Engines and Thermodynamics, Graz University of Technology, Styria, Austria
For several car manufactures, especially those located in the premium segment, this so-called sound-design has become an essential opportunity for defining and emphasizing brand image and vehicle characteristics [10].

Next to wind and rolling noise, the combustion noise plays a crucial part in vehicle acoustics. Especially in case of directly injected diesel engines, the excitation generated by the combustion process affects the overall noise level notably. In view of the combustion noise, the SI-engine can be seen as reference based on its smooth cylinder pressure curve. The objective in diesel engine engineering is the best possible approximation of pressure curve and rate of heat release to that of the SI-engine while maintaining the typical efficiency advantage inherent to diesel engines. Especially in the acoustically relevant part-load range, actual diesel engines show notable peaks in the noise characteristics, which are often sensed as "diesel knock". Currently, there is no ECU calibration which entirely prevents these peaks without deteriorating consumption and emission behavior.

Figure 1 shows the combustion noise level of a modern passenger car diesel engine. The calculation is carried out according to the Combustion-Noise-Level of the AVL List $\mathrm{GmbH}$, which will be specified in Sect. 2. A sharp increase in the part load area between 2 and 5 bar brake mean effective pressure is clearly recognizable and can also be noticed in the airborne noise during driving. Furthermore, analyzing transient operation modes, the indicated effect is intensified and leads to superelevations in the range of up to $5 \mathrm{~dB}(\mathrm{~A})$.

The target of the investigation is the optimization of the typical combustion noise of diesel engines by performing a profound and systematic analysis to show up coherencies and release mechanisms and to develop corrective actions and possible improvements. 


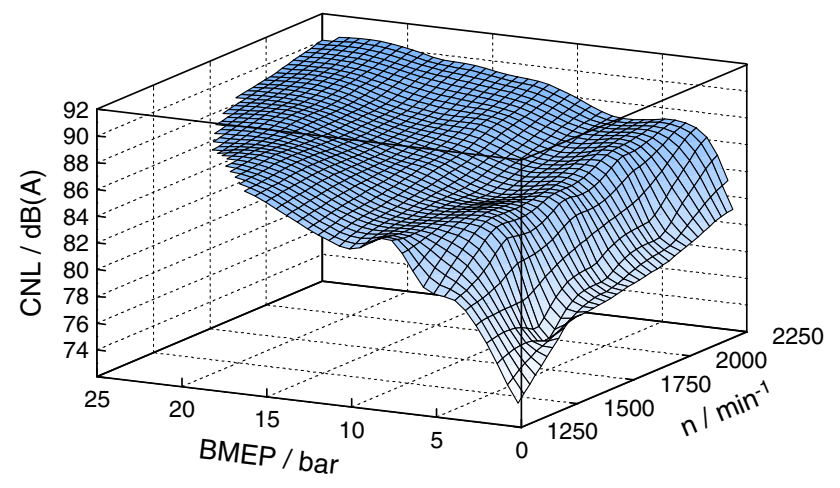

Fig. 1 Combustion noise of an actual passenger car diesel engine

\section{The combustion noise}

\subsection{Classification}

The overall vehicle shows a variety of noise sources, whereas wind and rolling noises as well as the drivetrain noise are particularly relevant. The latter can be separated in the gas-exchange noise generated by the intake and exhaust system, noises of the accessory drive system and the engine noise $[4,7,10]$. As the airborne sound radiated by the engine surface, the engine noise is the commanding source especially in low speed and load areas [10].

Airborne sound can be generated directly by air currents or indirectly by sound radiation of oscillating surfaces. A further separation of the indirect engine noise in a mechanic and a combustion part is possible $[1,2]$. The combustion noise encompasses all sounds caused by cylinder pressure, both directly by excitation of the cylinder walls as well as indirectly out of shock events in components subject to backlash $[4,10]$. The direct combustion noise dominates the acoustic behavior particularly in part load operation at low speeds $[3,9]$.

\subsection{Excitation by the cylinder pressure}

The pressure rise caused by the combustion acts like a shock and results in a broadband excitation of virtually all frequencies. Especially in case of direct injected diesel engines the high rates of heat release lead to accordingly high pressure gradients and thus to a high excitation $[5,8]$. The excitation spectrum depends on different parameters of the cylinder pressure. According to [3], frequencies up to $f=10 n$ are influenced by the maximum cylinder pressure $p_{\max }$, whereas the maximum pressure rise $\mathrm{dp} / \mathrm{d} \varphi$ is decisive in a frequency range as far as $f=40 n$ and the maximum velocity of the pressure rise $\mathrm{dp}^{2} / \mathrm{d}^{2} \varphi$ affects higher frequencies. Figure 2 illustrates this correlation.

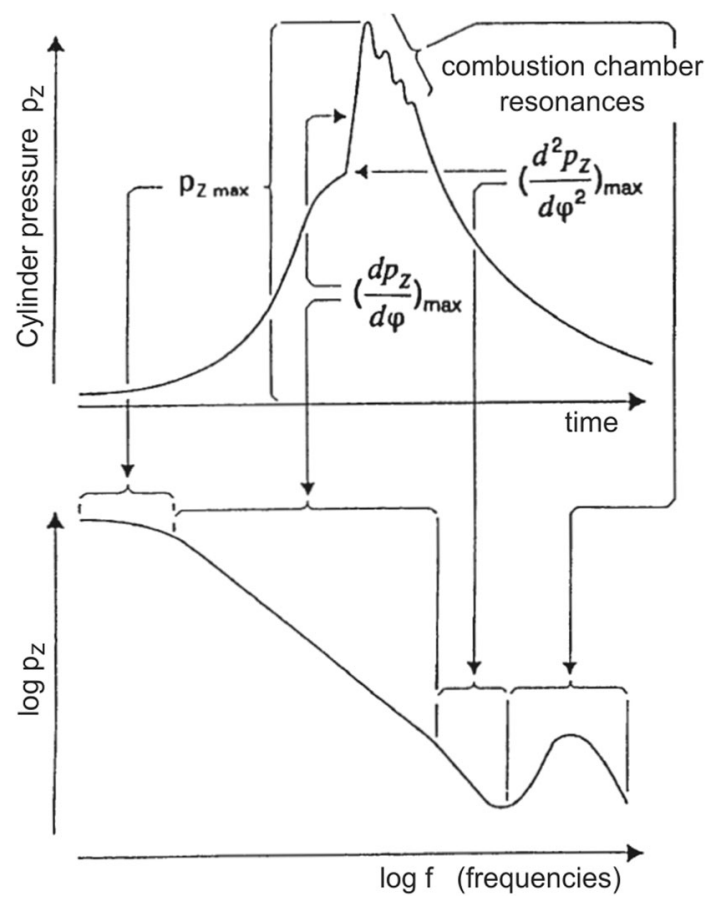

Fig. 2 Cylinder pressure excitation spectrum, translated from [3]

Taking the A-weighting into account and adding it to the obtained noise levels, the maximum pressure rise can be seen as the most relevant parameter [3]. Thus, an as low as possible excitation resulting in a good acoustic behavior can be achieved by generating a preferably smooth cylinder pressure curve.

The acoustic performance of a diesel combustion is characterized by a premixed amount of fuel, that, in the sequel, is converted quickly and thus noisy [6]. Hence, the previously mentioned acoustically ideal cylinder pressure profile does not exist in every operating point. This is especially true in part load operation, occurring particularly at low driving speeds like in urban traffic.

\subsection{Transmission path}

Originating in the excitation of the engine structure by the combustion process, the further transmission path of the combustion noise is illustrated in Fig. 3.

The gas force sets the surrounding structure into vibration. The transmission of these vibrations within the bodies is called structure-borne sound. Depending on material and shape of the body, there exists a frequency-dependent reduction, the so-called transmission function.

At the exterior of the engine, the surface vibrations result in propagating and audible fluctuations of the surrounding air density, the so-called airborne sound. The transmission from structure-borne to airborne sound is 
Fig. 3 Transmission path: combustion noise-airborne noise, translated from [2]

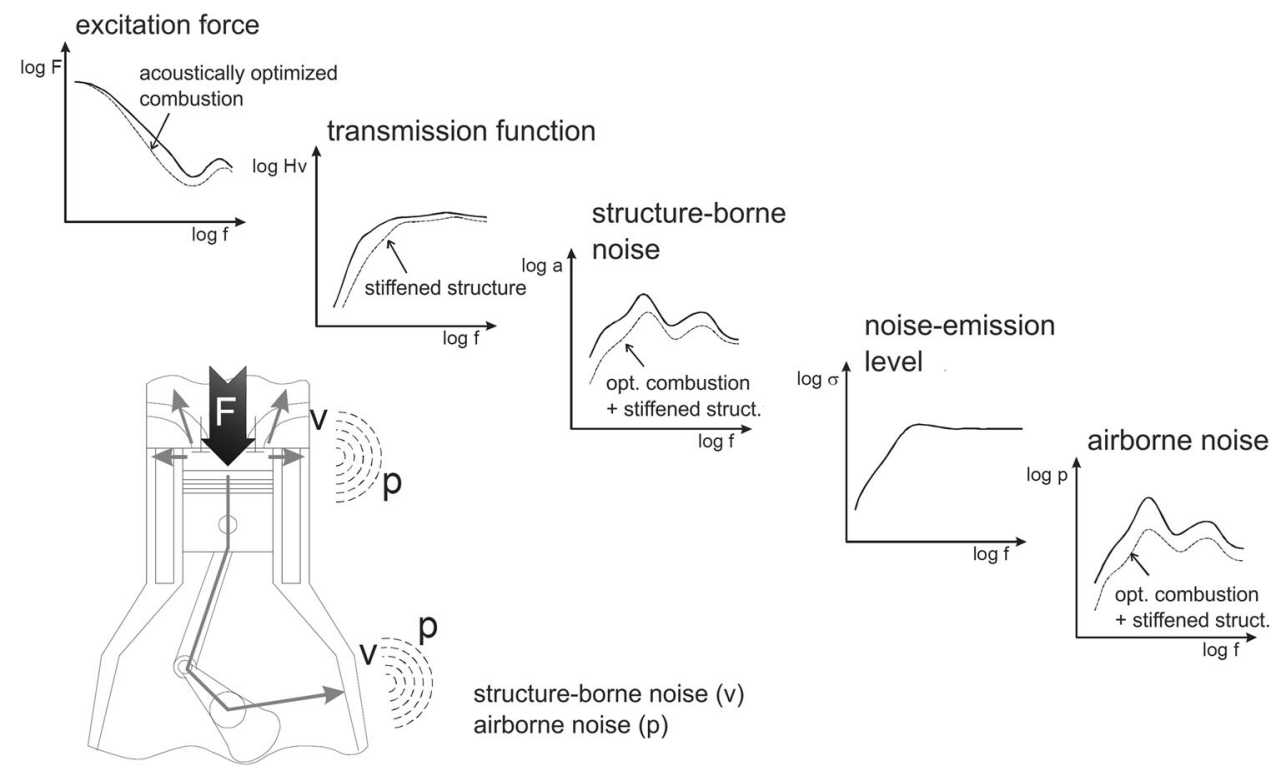

characterized by the noise-emission level, which is also frequency dependent.

Hence, the excitation of the engine structure by the combustion process is the origin of the noise generation and thereby a crucial point of application for optimizing the combustion noise.

\subsection{Calculation}

For calculating the combustion noise out of the cylinder pressure curve, several possibilities exist. The majority of these methods is based on a Fourier transform of the cylinder pressure. Subsequently, the result is modified by calculation of levels, application of various filters, ratings and summations.

Within the scope if this work, the Combustion-NoiseLevel (CNL) of the AVL List GmbH is used, which is also based on a Fourier transform of the cylinder pressure. The obtained result is converted into a third-octave spectrum. Using the human threshold of hearing, $2 \times 10^{-5} \mathrm{~Pa}$, levels are calculated. The transmission from the combustion chamber to the environment is considered by an empirical transfer function, the so called MFFR-function (Mean Freefield Response). Further on, the human perception is taken into account by applying the A-weighting. Finally, the rated levels are added up, resulting in an overall noise level.

\section{Methodology}

Basically, the methodical approach used in this work can be divided into investigations realized on an acoustic roller test bench using complete vehicles and investigations on an engine test bed. The carried out simulations are not part of this report.

\subsection{Investigation of the overall vehicle}

As a first step, the state-of-the-art was demonstrated by surveying several actual vehicles on an acoustic roller test bench. Therefore, three modern compact and mid-size cars with four-cylinder diesel engines, common-rail injection, a unitary displacement of 0.51 and a power range of 110-130 kW were investigated. Each car was provided with a considerable measuring equipment:

- High pressure indicating cylinder 1 including the measurement of injection timing for determining cylinder pressure, rate of heat release and combustion noise

- Measurement of multiple low-speed data, e.g. boost pressure, EGR rate, intake and exhaust temperature, air/fuel ratio, rail pressure, etc.

- Sensing of structure-borne noise characteristics via several attached acceleration sensors at the engine block, cylinder head and engine suspensions as well as in the interior at the seat rail and steering wheel

- Measuring of airborne noise characteristics in the engine compartment, the intake orifice, in front and behind the vehicle in a distance of $1 \mathrm{~m}$ together with measuring positions in the interior at the level of driver and passenger ear

The measurements were carried out on a dynamic acoustic roller test bed. The presence of low reflection walls (lining with absorbing wedges) permitted the depiction of a semi free-field room and hence influences on the airborne noise measurements by reflections were avoided. 
The noise phenomena mentioned in the introduction occur at steady-state operating points as well as in transient operation. In the latter case, the superelevation is even more distinct. On that account, both operating modes have been analyzed. To serve as basis for stationary behavior, a characteristic engine map with series calibration was measured in the acoustically interesting operating range from 1250 to $2250 \mathrm{~min}^{-1}$ and a brake mean effective pressure from 1 to 10 bar. The dynamic behavior was described by several run-ups and load steps, for example the BMEP change from 1 to 8 bar within one second at constant speed.

Beside the analyses of cylinder pressure and rate of heat release, the evaluation methodology of structure-borne and airborne measurement data was also given special attention. The received high-temporal-resolution data was primarily evaluated based on frequency spectra of Fourier analyses. Both the entire frequency band as well as the range from approximately 0.5 to $5 \mathrm{kHz}$ was used. This frequency range represents best the "diesel knock" noticed noise behavior.

The described measurement setup made it possible to calculate the combustion noise out of the cylinder pressure curve, evaluate the transmission path to the outer engine surface using the attached accelerometers and in further consequence illustrate the airborne sound audible in the engine compartment as well as in the vehicle interior and the surrounding. The similar setup used for all three vehicles enabled to draw a comparison amongst them. The obtained results are discussed in Sect. 4.

\subsection{Investigation on the engine test bed}

To understand the coherences between combustion process and noise generation, a profound analysis on an engine test bench was conducted, using one engine out of the earlier investigated vehicles. Besides the possibilities of a more extensive measuring equipment and a better conditioning of the test engine, the engine test bed enabled the specific modification of diverse parameters in the engine control unit.

Similar to the experiments on the roller test bench, a characteristic engine map in series calibration was recorded. In a first step that allowed to examine the transferability between roller and engine test bench and to prove the possibility to retransfer subsequently obtained results to the overall vehicle.

Besides the investigation of the series calibration, the primary focus was put on a profound sensitivity analysis by varying multiple parameters and evaluating their influence on combustion noise, consumption and emission behavior. The varied parameters have been boost pressure, charge air temperature, EGR rate, swirl valve position and several injection parameters like rail pressure, injection pattern or pilot quantity. To prevent interactions, only one parameter at a time was altered. That yielded to an isolated influence of the varied parameter on noise behavior, emission and consumption behavior. To maintain the same operating point during the variation, the overall fuel mass was adjusted appropriately.

\subsection{Ignition delay determination}

Mainly responsible for the combustion noise typical for diesel engines is the premixed amount of fuel, that, due to the already taken place mixture preparation, is converted quickly. The quantity of the premixed amount is determined primarily by the length of the ignition delay, which is specified as the period from start of fuel injection into the combustion chamber to start of combustion. The longer this period is, the more fuel can be injected and the bigger the amount of premixed fuel is.

The determination of the ignition delay requires the knowledge of start of delivery and start of combustion. The specification of these values is not trivial and sometimes ambiguous.

\subsubsection{Start of delivery}

The measurement of the injector power supply does not qualify for an accurate determination of the start of delivery, since start of supply and effective opening position of the injector needle show a time offset, dependent on rail pressure, point of injection and position as well as quantity of possible pilot injections. To precisely determine the start of injection in the present case, a measurement of the injection rate was performed.

The examined injector is kept in its original position in the injection system, the fuel, however, is injected into a wire filled with diesel and put under a certain counterpressure. This pressure should simulate the final compression state in the cylinder and thus best possible correspond to it. A pressure sensor, implemented directly after the injector, records the pressure rise based on the introduced fuel amount. The highly sensitive system architecture enables the detection of minimal injection quantities. The position of the pressure rise shows the exact start of injection in the current point of load.

\subsubsection{Start of combustion}

Usually, a certain amount of converted energy (for example, MFB5 or MFB10) is used for determining the start of combustion. In the present case, this method is unrewarding 
since, depending on the point of load, the actual start of combustion is in a varying distance. Furthermore, an automatized detection may contain errors based on an insufficient identification or rating of the actual start of combustion by the applied criteria. Hence, a check of the obtained results is necessary in every measurement point to make verified statements. In the present work, the start of combustion was determined manually for all examined measurement points, using the cylinder pressure curve including its first derivative as well as the rate of heat release.

The knowledge of start of injection and start of combustion enables to determine the ignition delay for different load points and the evaluation of its influence on the combustion noise. Using the measurement of the injection rate described before, an additional estimation of the fuel amount introduced during the ignition delay was possible by integrating the injection rate.

\section{Acoustic behavior of actual passenger car diesel engines}

Analyzing the measurement data of the three vehicles examined on the acoustic roller test bench demonstrates obviously an advancement in comparison to previous engines in virtually all fields of development, also in the combustion noise behavior. However, there are some map areas showing a sharp increasing noise level with higher BMEP. At all three vehicles the acoustic phenomena described in the introduction are measurable, only varying in their characteristics.

The following figures show maps of the combustion noise and the different transmission behavior of the three vehicles, the latter based on a comparison of structureborne and airborne noise results.

\subsection{Combustion noise}

Figure 4 illustrates the calculated combustion noise according to $\mathrm{CNL}$ as a function of load at a constant speed of $1750 \mathrm{~min}^{-1}$. The behavior at 1500 and $2000 \mathrm{~min}^{-1}$ is quite similar. All three vehicles show a remarkable rise of the combustion noise in the load range of approximately 1-6 bar BMEP, although the characteristic differs. Comparing vehicle 1 and 2, the increase in CNL of vehicle 1 is significantly more distinct and thus, despite a lower starting level, subjectively more noticeable. The increase of vehicle 3 is even more distinct, however, the behavior is characterized by an interruption caused by a change in the injection strategy between a BMEP of 2 and 3 bar. The abrupt decrease in combination with the following increase can be well noticed while driving.

The reason of the shown characteristics can be found in the different shapes of the main combustion in the pressure

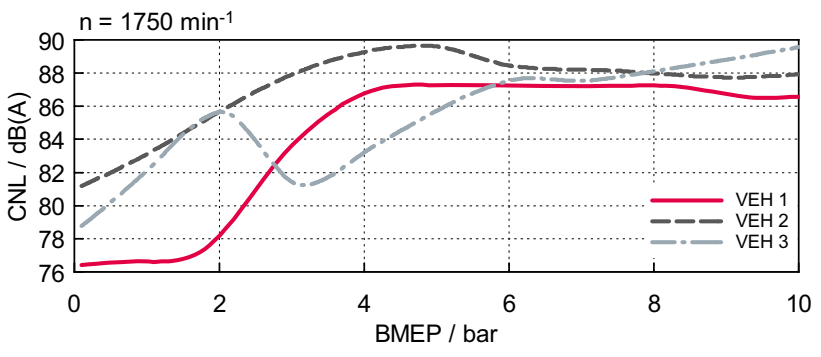

Fig. 4 Combustion noise: load variation at $1750 \mathrm{~min}^{-1}$

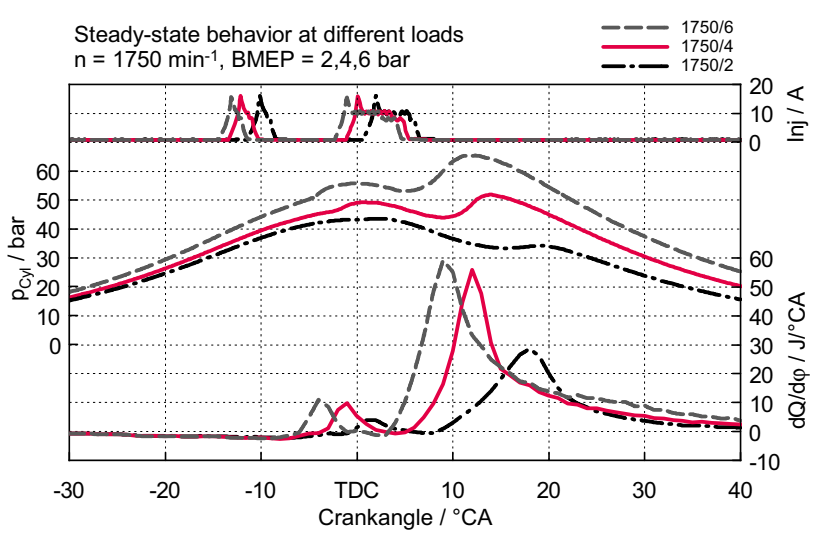

Fig. 5 Cylinder pressure and rate of heat release at $1750 \mathrm{~min}^{-1}$, vehicle 1

curve. In Fig. 5 cylinder pressure and rate of heat release are illustrated. It is identifiable that the main combustion becomes more dominant in the cylinder pressure between 2 and 4 bar BMEP, whereas the difference between 4 and 6 bar is considerably smaller. Decisive for the difference between 2 and 4 bar are primarily the EGR rate and the applied injection pattern. Both parameters affect the center of combustion and thereby the conversion rate, especially at low loads. The characteristics of the rate of heat release in Fig. 5 show the behavior vividly.

Figure 6a represents CNL-maps of the three evaluated vehicles. The high density of the isolines of vehicle 1 between 2 and 5 bar brake mean effective pressure as well as the maximum in the area of 5 bar of vehicle 2 can be mentioned. A further increase in load leads to a decrease of the combustion noise, which can also be seen in Fig. 4 . Caused by the altered injection strategy of vehicle 3 , the occurring maxima and minima are also visible. This demonstrates quite well the possible influence of the injection rate on the combustion noise.

\subsection{Transmission behavior}

The combustion and the related excitation are the origin of noise generation. However, perceptible for the driver and passers-by is the airborne noise radiated from the engine, 
Fig. 6 Combustion noise (a), transmission behavior, difference of vehicle 1 and 2 (b)
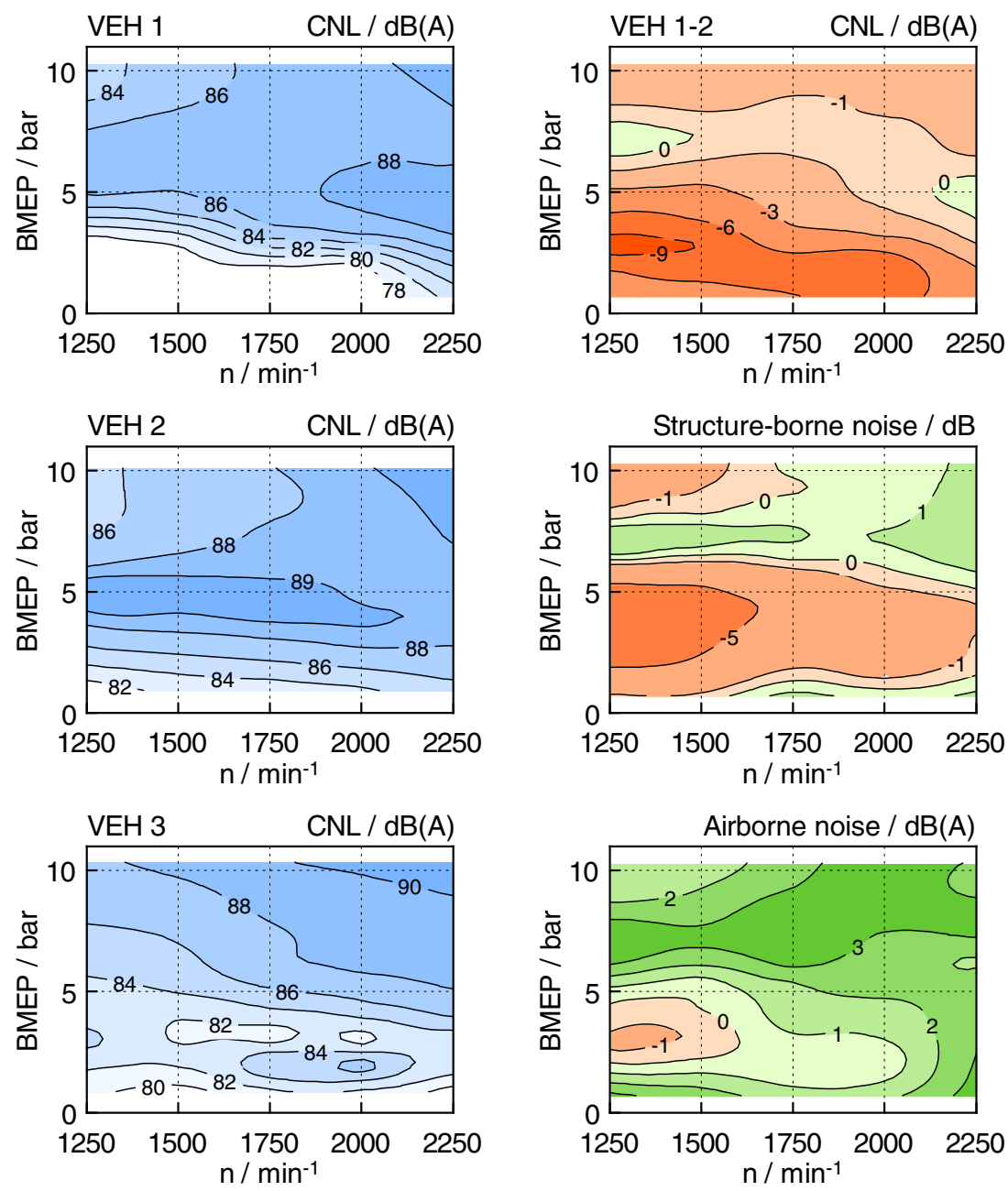

(a)

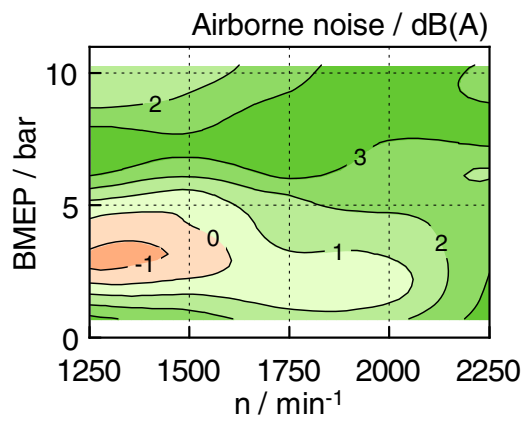

(b) caused by transmission of the combustion noise within the structure and subsequent emission.

The graphs in Fig. 6b display the difference of vehicle 1 and 2. It is obvious that, in case of the combustion noise, vehicle 1 has a better acoustic behavior in most of the considered map area than vehicle 2 . The advantage is partly up to $9 \mathrm{~dB}(\mathrm{~A})$. The analyses of the structure-borne noise at the outer engine surface and in further consequence the airborne noise in the engine compartment show that the advantage of vehicle 1 decreases during transmission. In case of the airborne noise, vehicle 2 is already less noisy than vehicle 1 in the majority of the evaluated points. The decided advantage of vehicle 1 concerning the combustion noise is lost by drawbacks in the transmission behavior and results in a higher noise level in the engine compartment. It has to be noted that in case of the measured airborne noise level additional noise shares like mechanical or flow noises are included. These noises may differ from vehicle to vehicle. Hence, the difference in the airborne noise level is not necessarily determined only by the combustion noise itself.

There is a good comparability of the airborne noise based on the same arrangement of the used microphones. In view of the structure-borne noise this cannot be clearly stated. Due to different shapes of the engine blocks and cylinder heads as well as varying positions of the accessories, the exactly same position of the acceleration sensors is not always realizable. Additionally, the transmission behavior and thus the recorded structure-borne noise differs depending on the selected position. In case of all three investigated vehicles, the structure-borne noise map shows a similar characteristic as those of the related combustion noise. Hence, it can be assumed that the chosen positions yield results, which reflect the excitation of the combustion process. 


\section{Combustion process analyses}

The results presented in Sect. 4 are based on a series calibration of the engine control unit. In this chapter, a closer analysis of the variation of several engine parameters is treated. Basis for the shown results is the measurement data received on the engine test bench.

Comparing the data from roller and engine test bench basically shows the same behavior. Quantities important for this work like CNL, boost pressure, injection timing, etc. are similar and therefore the retransformation of results to the overall vehicle is possible. Differences are revealed in several temperatures, for example the charge-air temperature, which can be led back to distinctions in conditioning. However, the influences of these parameters are known and can be considered appropriately.

\subsection{Sensitivity analysis}

The focus of the carried out engine test bench measurements was put on a profound variation of various engine parameters to develop the influences on the combustion noise behavior. In doing so, as described in Sect. 3, only one parameter at a time was varied to prevent interactions. Figure 7 shows the behavior of the combustion noise in dependence of a selection of parameters at three different operating points.

Generally, the load points 2000/2 and 2000/3 react quite similar, whereas at 2000/6 the influences decrease or even reverse.

This does not apply in case of a rail pressure variation, which leads in all three considered cases to an increasing combustion noise with higher injection pressure. The reason can be found in a better fuel atomization and hence a faster mixture preparation, which on the one hand reduces the ignition delay but on the other hand accelerates the following combustion process.

At low loads an increase of boost pressure yields in better ignition conditions and thus in a decreasing ignition delay. Simultaneously, the rate of heat release is increased, resulting in an earlier and faster combustion. The effect of the latter dominates, leading to a rising combustion noise. The ignition conditions are improved at 2000/6 as well, however, the influence on the conversion rate in this point is negligible. As a consequence, the advantage of the reduced ignition delay comes into affect and lessens the combustion noise. Nevertheless, the influence of the boost pressure on the noise behavior in this operating point is not extensive at all.

Considering the EGR rate at 2 and 3 bar brake mean effective pressure shows a minor effect of added exhaust gas on the combustion noise up to an amount of 30-40\%.
Only rather high EGR rates lower the noise level based on a marked slowdown of the combustion process. At 2000/6 there is only a nominal impact of the added exhaust gases, caused by a reverse behavior at higher loads. In these operating points an increase of the EGR rate causes an increasing ignition delay and in the sequel a higher premixed fuel amount, which can be converted quickly. The center of combustion is barely influenced.

The position of the main injection at 2 and 3 bar brake mean effective pressure affects the combustion noise notably. An injection past the top dead center causes a lower combustion noise level due to the decreasing pressure level in the combustion chamber, accompanied by deteriorating conversion conditions. At 2000/6 a stagnation respectively reversal of the behavior can be observed, based on the same effects as mentioned at the variations of boost pressure or EGR rate.

In general, especially in the low-load range up to approximately 4 bar brake mean effective pressure the variation of several parameters results in a distinct response of the combustion noise. Major relevance have rail and boost pressure, EGR rate and the position of the main injection. Remarkable is the fact that in this load area a decrease in the ignition delay mostly corresponds with a higher rate of heat release and thus with an increase in the combustion noise level. The benefit of lower premixed fuel amounts does not come into affect in this load area. Hence, an all over decrease of the ignition delay is not a priori advantageous.

\subsection{Ignition delay and premixed amount of fuel}

The calculation of the occurring ignition delays by means of an exact determination of start of injection and start of combustion shows an interesting map behavior, illustrated in Fig. 8.

In the area of 5 bar brake mean effective pressure a distinct maximum is perceptible, covering the whole observed speed area and resulting in ignition delays up to $5{ }^{\circ} \mathrm{CA}$.

The drop at higher loads can be explained by better conditions for mixture preparation and combustion procedure, such as an increasing rail and boost pressure. Additionally, the applied EGR rate decreases. In the BMEP range of 1-3 bar, the EGR rate is the main cause for the rising ignition delays, which could be shown by several experiments and variations. Further on, a homogenization of the ignition delay between 1 and 3 bar can be achieved by an increase in boost pressure. However, based on the used hardware tight constraints are set.

The fuel mass injected during the ignition delay shows a behavior similar to the ignition delay itself. The increasing 
$2000 / 2$

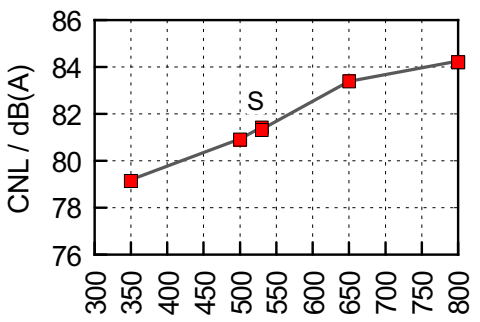

Rail pressure / bar

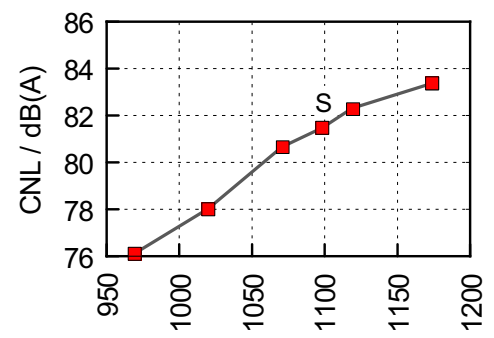

Boost pressure / mbar
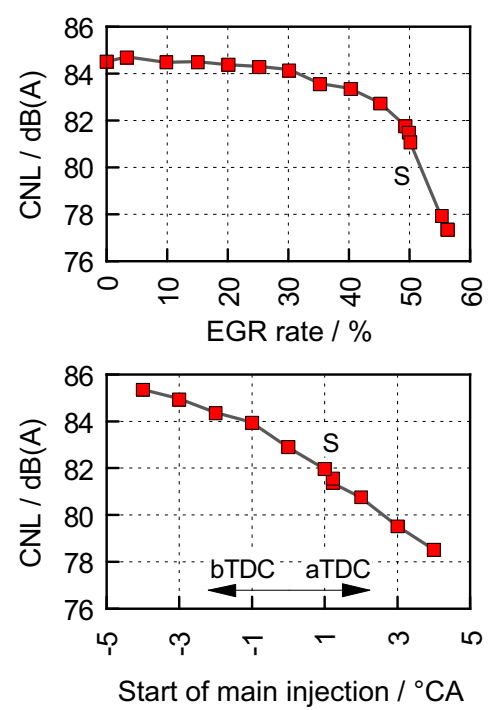

$2000 / 3$

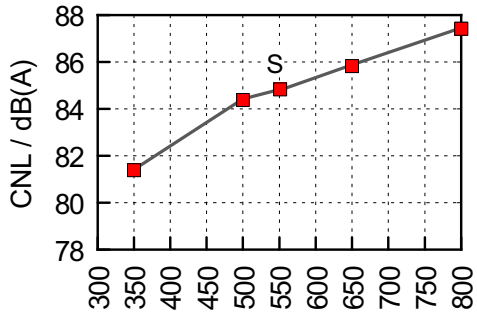

Rail pressure / bar

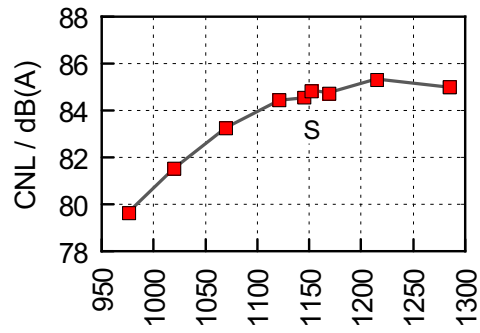

Boost pressure / mbar
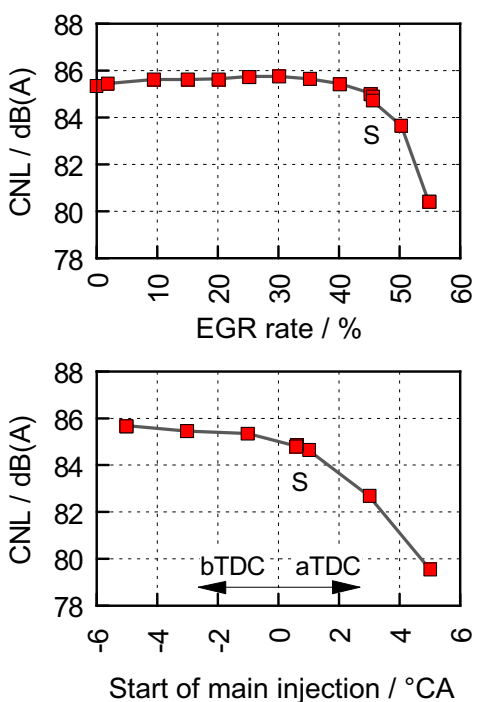

$2000 / 6$
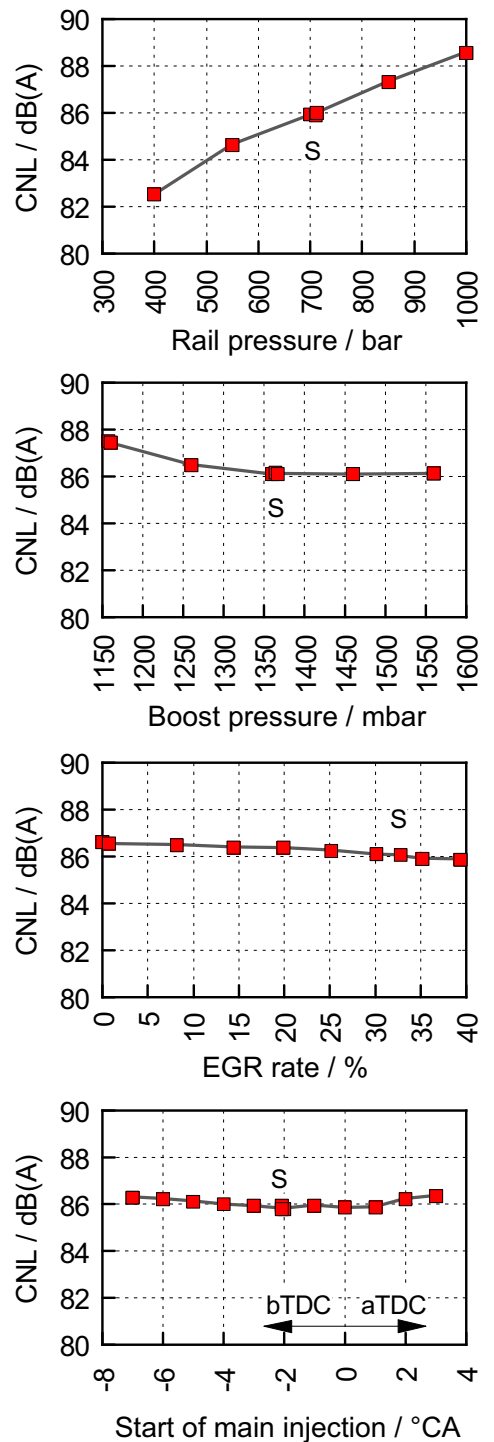

Fig. 7 Parameter variation and its effects on the combustion noise, $\mathrm{S}=$ series calibration

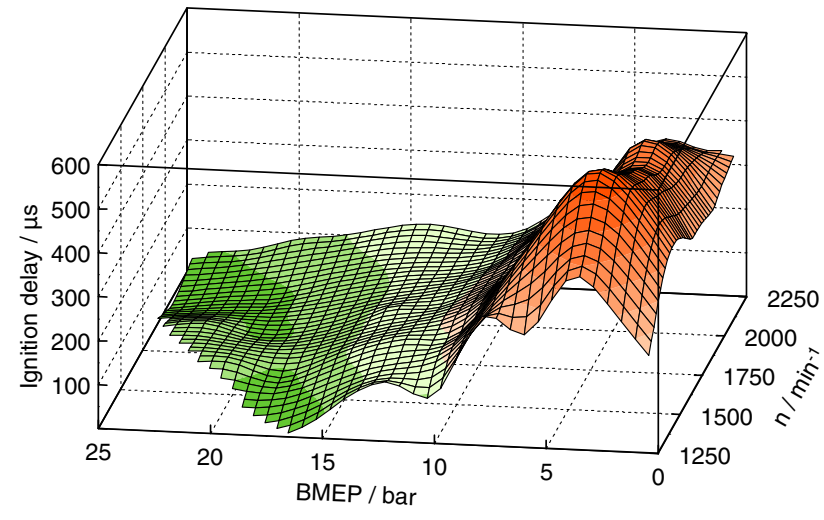

Fig. 8 Map of the ignition delay rail pressure at higher load points does not have a crucial impact on that.

\subsection{Transient behavior}

In transient operation, the combustion noise behavior in certain cases deteriorates sharply. Figure 9 illustrates that using a comparison of stationary measurement points and a load step. The details of the load step are shown in the diagram. The noise level in dynamic operation is consistently higher with a superelevation up to $4 \mathrm{~dB}(\mathrm{~A})$ relating to steady-state operation.

A closer analysis of the measured data implies two main causes for this noise peak. These are the EGR rate control 


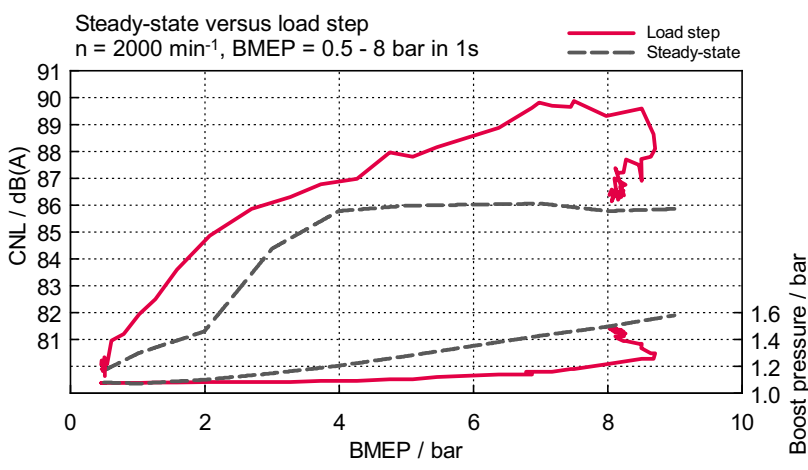

Fig. 9 Transient behavior: comparison of CNL and boost pressure

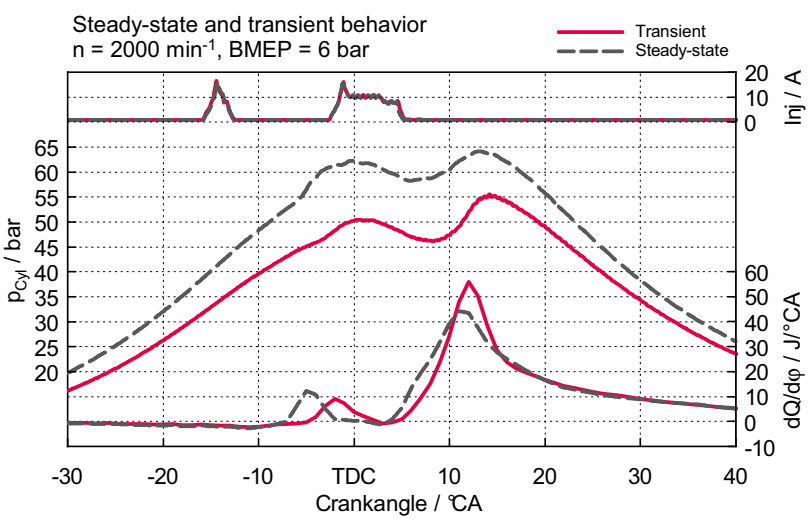

Fig. 10 Transient behavior: cylinder pressure and rate of heat release

as well as the delayed boost-pressure buildup. The EGR rate especially affects the range up to about 4 bar brake mean effective pressure, whereas the boost pressure is the cause in the area of 4-8 bar.

The boost pressure development is shown in Fig. 9. It can be recognized that, up to a BMEP of approximately 6 bar, there is no boost pressure at all in the transient operation and the engine works almost naturally aspirated. The impact on cylinder pressure and rate of heat release can be seen in Fig. 10. The missing boost pressure in transient operation causes an extended ignition delay and in the sequel a steeper increase in both curves. This behavior corresponds with the one shown in the sensitivity analysis, see Fig. 7.

\section{Summary and outlook}

The present report analyzes the combustion process of several modern passenger car diesel engines with respect to their noise behavior. The primary focus is put on the combustion noise as main reason for the noise excitation. In addition, the transmission behavior from the combustion chamber to the engine compartment is examined, using several structure-borne and airborne measuring points.
In terms of the applied methodology, both measurements on an acoustic roller test bench as well as on a conventional engine test bench are conducted. In addition to an analysis of the series calibration also the influence of several parameters on the combustion noise is investigated in detail together with the development of an exact determination of the ignition delay.

The results of the examined vehicles show the appearance of a sharply increasing noise level in part-load operation, which is typical for modern diesel engines. The particular shape is dependent on the used injection strategy and is reflected in the cylinder pressure and the rate of heat release. In steady-state operation especially rail and boost pressure, EGR rate and position of the main injection are relevant to the combustion noise behavior, whereas in dynamic operation the delayed boost-pressure buildup is the main cause. Distinct differences are revealed in the transmission behavior of the vehicles.

In the further course of this research project an optimization of the noise behavior based on the obtained insights should be performed. Conceivable possibilities are adjustments in the engine control unit calibration as well as modifications of the applied hardware. Especially in case of an alternate calibration drawbacks in efficiency and emission behavior have to be considered. Promising changes in hardware concern the charging unit and the injection system, for instance. Finally, obtained improvements should be validated in the overall vehicle.

Acknowledgments Open access funding provided by Graz University of Technology.

Open Access This article is distributed under the terms of the Creative Commons Attribution 4.0 International License (http://crea tivecommons.org/licenses/by/4.0/), which permits unrestricted use, distribution, and reproduction in any medium, provided you give appropriate credit to the original author(s) and the source, provide a link to the Creative Commons license, and indicate if changes were made.

\section{References}

1. Barba, C.: Erarbeitung von Verbrennungskennwerten aus Indizierdaten zur verbesserten Prognose und rechnerischen Simulation des Verbrennungsablaufes bei Pkw-DE-Dieselmotoren mit Common-Rail-Einspritzung. Dissertation, Swiss Federal Institute of Technology in Zürich (2001)

2. Finger, K.: Untersuchungen zur Kraftanregung durch die Verbrennung beim direkteinspritzenden Common-Rail Dieselmotor unter Berücksichtigung des Körperschallübertragungsverhaltens. Dissertation, Darmstadt University of Technology (2001)

3. Flotho, A., Spessert, B.: Geräuschminderung an direkteinspritzenden Dieselmotoren-Teil $1 \&$ Teil 2. Automob. Ind. 33, 255-261, 561-565 (1988)

4. Heuer, S.: Verbrennungsgeräusch des direkteinspritzenden Hubkolbenmotors. Dissertation, RWTH Aachen University (2001) 
5. Hrdina, D., Bargende, M., Felbinger, F., Lang, J.: Störgeräusche bei Motoren mit hohen Druckgradienten. MTZ Motorentechnische Z. 74(12), 1010-1016 (2013)

6. Merker, G.P., Schwarz, C.: Grundlagen VerbrennungsmotorenSimulation der Gemischbildung, Verbrennung, Schadstoffbildung und Aufladung. 4. revised and updated edition, Vieweg+Teubner Verlag (2009)

7. Priebsch H.: Akustik für Motor und Fahrzeug. Lecture notes, Graz University of Technology (2013)
8. Rumplmayr, P.: Verbrennungsgeräuschanalyse eines Pkw-DIDieselmotors. Master Thesis, Graz University of Technology (2014)

9. Spessert, B.: Geräuschreduktion von Viertakt-Diesel- und Ottomotoren-Rückblick und Stand der Technik. MTZ Motorentechnische Z. 60(7/8), 508-517 (1999)

10. Zeller, P.: Handbuch Fahrzeugakustik-Grundlagen, Auslegung, Berechnung, Versuch. 2. revised edition. Vieweg+Teubner Verlag (2012) 